\title{
The language is Alive!: análise crítica de unidade didática de livro do PNLD-LEM
}

\section{Raquel Salcedo Gomes}

Doutoranda em Linguística Aplicada na UNISINOS

- Universidade do Vale dos Sinos e em Informática

em Educação na UFRGS - Universidade Federal

do Rio Grande do Sul; Professora do Ensino

Superior e da Educação Básica na IENH -

Instituição Evangélica de Novo Hamburgo; Novo

Hamburgo; Rio Grande do Sul; Brasil.

salcedogomes@gmail.com

Resumo: Desde 2011, o componente curricular Língua Estrangeira vem sendo contemplado pelo Programa Nacional do Livro Didático com livros distribuídos para estudantes de escolas públicas de educação básica do Brasil. Considerando esse momento da política educacional brasileira na direção da qualificação de materiais didáticos, desenvolvo a análise da Unit 1 do livro Alive! para o 90 ano do ensino fundamental da perspectiva do professor (RAMOS, 2009), isto é, trazendo para a análise as necessidades e objetivos de aprendizagem de uma turma de alunos na qual 0 livro será utilizado nas aulas de língua estrangeira no ano de 2014.

Palavras-chave: Programa Nacional do Livro Didático, Teoria Sociocultural, Ensino e Aprendizagem de LE
Abstract: Since 2011, the Foreign Language curriculum component is being contemplated by the National Textbook Program with course books distributed to students in public elementary schools in Brazil. Considering this stage of Brazilian educational policy towards the qualification of teaching materials, I have developed the analysis of Unit 1 of the book Alive! for the 9th grade of elementary school from the teacher's perspective (RAMOS, 2009), that is, taking into consideration the learning needs and goals of a group of students in which the book will be used in foreign language classes in 2014.

Keywords: National Textbook Program, Sociocultural Theory, EFL Teaching and Learning 



\section{Introdução: o PNLD-LEM}

Desde 2011, o componente curricular Língua Estrangeira (LE) vem sendo contemplado pelo Programa Nacional do Livro Didático (PNLD) com livros distribuídos para todos os estudantes de escolas públicas de educação básica do Brasil. Para alguns pesquisadores, a expectativa deste ingresso é a de maior proeminência e reconhecimento do papel do ensino de LE na escola, contribuindo para mudanças que visem sua qualificação (SARMENTO; SILVA, 2012).

Já em sua segunda edição no ano de 2013, mediante consulta aos Guias do Livro Didático, professores puderam escolher as coleções didáticas mais pertinentes a seu contexto de atuação. Enquanto na edição de 2011 podiase escolher entre duas coleções para a língua inglesa, na edição de 2013, o número de coleções aprovadas aumentou para três.

$\mathrm{O}$ estudo de materiais didáticos no ensino de LE não é recente, acompanhando o campo da Linguística Aplicada à Educação desde o delineamento da área (GRAY, 2013). No entanto, cabe afirmar sua relevância no contexto brasileiro atual, visto que, graças ao PNLD, as coleções didáticas de LE passaram a estar mais presentes nas salas de aula da educação pública básica do território brasileiro e que publicações recentes têm indicado a necessidade de mais análises de materiais didáticos a fim de complementar o trabalho desenvolvido (GRAY, 2013; DIAS, 2009). Cumpre, neste contexto, registrar que os materiais didáticos servem a interesses que excedem aqueles puramente pedagógicos, uma vez que alimentam um mercado editorial e desempenham papéis que não podem ser descolados das dimensões políticas, sociais e econômicas dos contextos em que são produzidos e utilizados.

Rajagopalan (2012) adverte a respeito de seu papel eminentemente político, a serviço de ideologias 
que buscam estratégias de conquista ou manutenção de dominações culturais e disputas por diferentes formas de poder. Pode-se afirmar que também por estes motivos, além do objetivo principal de qualificar o ensino, os editais do PNLD fornecem princípios gerais e critérios rígidos para a inclusão de coleções candidatas no programa.

Os princípios gerais do PNLD estão fundamentados na Constituição Federal, Lei de Diretrizes e Bases da Educação, Estatuto da Criança e do Adolescente, Diretrizes Curriculares Nacionais e resoluções do Conselho Nacional de Educação, sem deixar de considerar progressos efetuados na academia nos campos das teorias da aprendizagem e da psicologia cognitiva (EDITAL PNLD, 2013, p. 52). Também são enfatizados os direitos de grupos sociais minoritários ou historicamente desfavorecidos e o respeito à diversidade cultural, com vistas à formação de cidadãos atuantes e defensores da democracia. Tais princípios são eliminatórios nos processos de seleção e avaliação das coleções didáticas ingressantes no programa, o não cumprimento de qualquer deles acarreta sua exclusão, sem que elas façam parte do processo de avaliação qualitativa.

No que tange aos critérios de avaliação eliminatória qualitativa das coleções, são definidos critérios comuns a todas as áreas e também critérios específicos a cada uma delas. Os critérios comuns são: 1. respeito à legislação, às diretrizes e às normas oficiais relativas ao ensino fundamental; 2. observância de princípios éticos necessários à construção da cidadania e ao convívio social republicano; 3. coerência e adequação da abordagem teórico-metodológica assumida pela coleção no que diz respeito à proposta didático-pedagógica explicitada e aos objetivos visados; 4. correção e atualização de conceitos, informações e procedimentos; 5 . observância das características e finalidades específicas do manual do professor e adequação da coleção à linha pedagógica 
nele apresentada; e 6. adequação da estrutura editorial e do projeto gráfico aos objetivos didático-pedagógicos da coleção (EDITAL PNLD, 2013, p. 55).

Os critérios específicos da área de LE foram elaborados tendo em vista os seguintes objetivos da aprendizagem de LE no ensino fundamental: 1. vivenciar experiências de interação pelo uso de uma língua estrangeira, no que se refere a novas e diversificadas maneiras de se expressar e de ver o mundo; 2. refletir sobre costumes, maneiras de agir e interagir em diferentes situações e culturas, em confronto com as formas próprias do universo cultural do seu entorno, de modo a perceber que o mundo é plural e heterogêneo e entender o papel de cada um como cidadão; 3 . construir conhecimento sobre a língua estrangeira estudada, em particular, quanto às diferentes finalidades de uso dessa língua, conforme os diversos âmbitos sociais e regionais, a partir do estatuto dos parceiros em interação, o lugar e o momento legítimos, e seus possíveis modos de organização verbal, não verbal e verbo-visual, que remetem a uma finalidade reconhecida social e historicamente; 4. reconhecer processos de intertextualidade como inerentes às formas de expressão humana, às manifestações humanas, quer se manifestem por meio do verbal, não verbal ou verbo-visual; 5 . desenvolver consciência linguística e crítica dos usos que se fazem da língua estrangeira que se está aprendendo. Os critérios específicos da avaliação de coleções didáticas de LE para os anos finais do ensino fundamental no PNLD, conforme o Edital de 2013, podem ser encontrados no Anexo deste texto.

Considerando que todos estes critérios já são levados em conta na avaliação e seleção das coleções didáticas no âmbito macro do PNLD do ponto de vista do material em si, proponho, no presente texto, a análise da Unit 1 do livro Alive! para o $9^{\circ}$ ano do ensino fundamental da perspectiva do professor (RAMOS, 2009), 
isto é, trazendo para a análise as necessidades e objetivos de aprendizagem dos alunos e da escola na qual o livro será utilizado nas aulas de língua estrangeira no ano de 2014. O faço a partir de uma perspectiva sociocultural de ensino e aprendizagem de línguas, na qual materiais didáticos assumem um papel importante para o ensino de língua estrangeira porque atuam como artefatos culturais que medeiam semioticamente práticas sociais e negociações de sentido imprescindíveis à aprendizagem e ao desenvolvimento humanos, o que vai ao encontro dos critérios qualitativos gerais e específicos dos editais do PNLD. A opção por tal perspectiva teórica para a análise se dá ainda porque ela possibilita o estudo da língua e da aprendizagem de línguas a partir dos contextos sociais, prevendo que os elementos formais da linguagem estão sempre sujeitos aos usos e objetivos comunicacionais da produção discursiva, o que justifica também a análise aqui realizada, com vistas ao contexto em que o livro didático será utilizado. Pode-se afirmar que tal perspectiva se faz presente nas diretrizes teórico-pedagógicas da coleção didática na medida em que é abordada nos documentos oficiais e diretrizes para o ensino delínguas disponibilizados pelas instâncias administradoras da educação brasileira, a exemplo dos Parâmetros Curriculares, aos quais a coleção deve se alinhar a fim de que seja aprovada para o PNLD.

A escolha desta coleção didática para a presente análise ocorreu por razões de natureza teórico-científicas e pragmáticas. A coleção Alive! foi escolhida por mim para ser adotada nas escolas em que atuo como docente de LE porque recebeu os melhores níveis de qualificação até agora de acordo com os critérios de avaliação especificados no edital do PNLD 2014. Ademais, esta coleção estará em uso a partir do ano letivo de 2014 em turmas dos anos finais do Ensino Fundamental de todo o Brasil.

Na próxima seção, discuto a fundamentação teórica que orienta a análise aqui empreendida, apresentando o que 
entendo serem as especificidades de um viés sociocultural para o ensino e a aprendizagem de LE e refletindo sobre como tal viés influi na concepção de materiais didáticos e seu papel no processo de formação tanto de alunos quanto de professores. Em seguida, apresento a metodologia de análise adotada, advinda de uma proposta de análise de unidades didáticas da perspectiva do professor, elaborada por Ramos (2009). À apresentação e discussão da metodologia prossegue-se à análise da referida unidade didática e às considerações finais.

\section{Um viés sociocultural para o ensino e a aprendizagem de LE}

A teoria sociocultural, que tem nos estudos de Lev Vygotsky seu marco inaugural, prevê uma concepção do livro didático como instrumento ou artefato cultural de mediação que auxilia o professor em seu processo de internalização e, consequentemente, de aprendizagem das práticas metodológico-pedagógicas que utiliza e aperfeiçoa, bem como de suporte às aprendizagens dos alunos.

De acordo com Johnson (2009, p. 1), em um viés sociocultural, a cognição humana superior no indivíduo tem suas origens na vida social e as atividades socioculturais são consideradas como os processos essenciais nos quais tal cognição é formada. Assim, ainda conforme a autora, assume-se que a cognição humana se desenvolve através do engajamento em atividades sociais, construídas socialmente através da mediação de materiais, signos e símbolos que possibilitam formas singularmente humanas de pensamento avançado.

Segundo Vygotsky (1996, p. 17), as atividades dos aprendentes são inicialmente mediadas por outras pessoas ou artefatos, mas depois ficam sob seu próprio domínio à medida em que se apropriam de determinados recursos para regular suas atividades, o que só é 
possível através da língua, que está inicialmente apenas no meio social, mas da qual o indivíduo se apropria, internalizando-a e organizando seu próprio pensamento. Desse modo, a teoria sociocultural propõe inovações ao estudo do desenvolvimento humano porque afirma um imbricamento recíproco entre pensamento e linguagem, indispensável a este desenvolvimento.

No que diz respeito a essa teoria, portanto, professores e alunos são vistos como aprendentes que desenvolvem suas aprendizagens na interação interpessoal e com artefatos e sistemas semióticos mediadores, de modo que a aprendizagem é considerada um processo dinâmico e de hierarquias flexíveis, pois tanto professores, alunos e artefatos modificam uns aos outros e são modificados no decorrer desse processo. Lantolf (2004) reforça o caráter dialógico do desenvolvimento cognitivo, que não se situa apenas na interação com pessoas, mas na relação com artefatos de mediação, como são os livros didáticos.

Em uma perspectiva sociocultural, o sentido não reside na língua em si mesma, mas em seu uso social, de maneira que o desenvolvimento cognitivo é caracterizado como a aquisição e manipulação de instrumentos e conhecimentos culturais, dos quais o mais poderoso é a língua. À língua, objeto de ensino das aulas de LE, também é dado este caráter dinâmico, uma vez que é concebida como sistema de signos mediadores do pensamento e do desenvolvimento cognitivo, considerada não apenas em seus aspectos intrinsecamente linguísticos, mas também discursivos e pragmáticos, de modo que a cultura, os contextos locais e a história são levados em conta como componentes deste objeto de ensino (LANTOLF; APPEL, 1994).

Neste sentido, o ensino de estruturas gramaticais não dá conta do que é o ensino de língua em uma perspectiva sociocultural, pois a gramática torna-se apenas componente do objeto de ensino língua e deve 
ser abordada sempre a serviço do uso da língua em práticas sociais situadas, com finalidades específicas. À língua somam-se as dimensões não-verbais, visuais, prosódicas, sonoras, de formatação e do suporte nos quais gêneros de textos autênticos são ensinados visando propósitos comunicacionais concretos, de maneira que o objeto de ensino passa a ser a linguagem em seu sentido mais amplo e não somente a língua enquanto sistema de signos descolado de seus contextos pragmáticos de uso. Convém reiterar que, em uma perspectiva sociocultural, a aprendizagem e o desenvolvimento são considerados processos mutuamente imbricados, e que a internalização de estruturas linguísticas e sua apropriação aos contextos de uso adequados não é mera apropriação, mas transformação desses contextos e dos próprios aprendentes (OSS, 2013, p. 103).

Uma vez que a aprendizagem não surge ocasionalmente do próprio sujeito, como se ele passasse por estágios definidos e estanques de maturação, os contextos nos quais interage, as pessoas com quem convive, seus modos culturais de convivência e suas relações com os mais variados artefatos continuarão interferindo nas práticas do aprendente, seja ele o professor ou o aluno, mesmo após ter deixado de interagir nesses contextos ou com estes objetos (OSS, 2013, p. 104).

No entanto, após anos de consolidação da teoria sociocultural no campo do ensino de LE, corroborado pela presença de uma concepção sociointeracional de ensino e aprendizagem de línguas preconizada em documentos como os Parâmetros Curriculares Nacionais, o ensino de gramática, subjacente a uma concepção de língua como um sistema de signos fechado, ainda se faz bastante presente em práticas e concepções teóricas de professores, alunos e mesmo de materiais didáticos, o que justifica a continuidade dos estudos e pesquisas a partir de um viés sociocultural. 
Conforme enfatiza Johnson (2009, p. 13), se for abraçada a noção de que a aprendizagem é social, situada em contextos físicos e sociais, e distribuída entre as pessoas, artefatos e atividades, a formação precisa de um novo delineamento das fronteiras do que normalmente é definido como desenvolvimento, de modo que uma perspectiva sociocultural na formação de professores de LE envolve mudanças, e não a simples reprodução de teorias, métodos e atividades de ensino.

Assim, a análise de materiais didáticos para $o$ ensino e a aprendizagem de LE tende a qualificar as interações, processos e mediações que ocorrem nas várias dimensões da educação linguística, pois pode oportunizar transformações, reconceitualizações e mudanças nas concepções teóricas e práticas de professores e de autores de materiais didáticos, culminando, em alguma medida, na qualificação das ofertas educacionais e práticas pedagógicas desenvolvidas com os estudantes, públicoalvo do ensino e aprendizagem de LE.

\section{Metodologia}

Primeiramente, analiso a unidade através de uma forma de avaliação que Ramos (2009) adota de Cunningsworth (1995, p. 1-2), denominada de impressão geral, que é realizada folheando-se rapidamente o livro didático e analisando sua organização pedagógica geral.

Em seguida, tomo como categorias de análise os critérios para a avaliação de unidades didáticas estabelecidos por Ramos (2009, p. 184-185), intentando analisar a Unit 1 do livro Alive! para o 9o ano do ensino fundamental da perspectiva do professor. Ramos define os seguintes critérios:

2.1 Público-alvo: a quem a unidade se dirige? (faixa etária, sexo, conhecimento prévio da língua, contexto geopolítico local); 
2.2 Objetivos da unidade: quais são? Estão explícitos ou implícitos? São alcançáveis? Contribuem para a formação do cidadão?

2.3 Recursos: há indicações do que será usado ou necessário para o desenvolvimento da unidade?

2.4 Visão de ensino/aprendizagem e de linguagem: quais são?

2.5 Syllabus subjacente à unidade: estrutural? Funcional? Situacional? De gêneros? De tarefas? Outros?

2.6 Progressão dos conteúdos: do mais fácil para o mais difícil? Do conhecimento de mundo para os conhecimentos de organização textual e sistêmicos? Como o conhecimento estratégico aparece? Como a gramática é focalizada? Isoladamente? Contextualizada?

2.7 Quanto aos textos: são didáticos, autênticos ou adaptados com simplificações? São diversificados tanto com relação aos tipos como aos tópicos? São contextualizados? Abordam temáticas abrangentes? Focalizam ou promovem interdisciplinaridade e/ou transversalidade? São adequados à faixa etária? Apresentam qualidade gráfica e visual no que concerne a ilustrações, diagramação, etc? São adequados às atividades propostas?

2.8 Quanto às atividades: os objetivos estão implícitos ou explícitos? As instruções são claras? Dependem do professor para sua aplicabilidade? Têm enunciados que verificam o conhecimento do aluno ou que conduzem à prática e à aprendizagem? São do tipo controladas ou não controladas? Exercícios? Tarefas? De compreensão para a produção da prática de habilidades para o uso? Promovem interação? Colaboração? Autoestima? Entretenimento? Geram solução de problemas? Promovem o desenvolvimento de habilidades cognitivas? São muitas? Suficientes para os objetivos propostos? Poucas? 
2.9 Material suplementar: é necessário? É possível?

2.10 Flexibilidade da unidade: propicia adaptações? Uso de outra sequência etc?

2.11 Teachers notes:possui? Indica procedimentos para aplicação das atividades e gerenciamento de sala de aula? Justificativas para o material? Respostas para as atividades?

A opção por adotar esta metodologia de análise se dá devido a seu potencial de avaliação do livro didático no que concerne ao contexto social em que será realmente utilizado por professora e estudantes, o que se alinha às concepções de linguagem e ensino de línguas de uma perspectiva teórica sociocultural, que destacam a relevância dos contextos sociais locais, no qual ocorrem as interações. Tal análise permite um cotejo das características da coleção, que supostamente abarca todos os critérios de qualidade supracitados em conformidade ao edital do PNLD, a serviço do processo educacional que ocorrerá junto a uma turma específica do 9o ano do ensino fundamental.

Esse viés analítico possibilita avaliar a própria metodologia como alinhada a uma concepção sociocultural de ensino e aprendizagem de línguas, visto que essa perspectiva teórica tende a valorizar as noções de ensino e aprendizagem enquanto processos ocorridos no âmbito da educação, em uma tentativa de escapar das análises que avaliam seus resultados como positivos ou negativos de acordo apenas com seu produto final, geralmente dicotômico: o sucesso ou o fracasso na aprendizagem, a aprovação ou a reprovação.

Acredito que tais enfoques limitados aos resultados finais apenas podem ser prejudiciais à educação e ao desenvolvimento na medida em que buscam totalizar aspectos complexos do ensino e da aprendizagem que 
são permeados por diversos fatores que ficam invisíveis, reduzidos a apenas uma categoria conclusória. A ênfase nos processos permite a observação dos pormenores, dos fatores que levam ao alcance de objetivos que podem não ser o principal, mas que inegavelmente promovem a aprendizagem, ainda que não plenamente aquela inicialmente almejada.

\section{Análise}

No que concerne à análise da impressão geral, para uma melhor compreensão da organização pedagógica, cumpre explicitar que o plano didático do livro Alive! divide-se em quatro partes a serem desenvolvidas ao longo do ano letivo, cada uma delas subdividida em duas unidades didáticas. Elaborado para 80 horas anuais de aulas de LE, o livro de cada ano letivo (do 6 o ao 9o ano) está organizado em torno de um tema e de um projeto de trabalho com um gênero textual, em um sistema de produção de portifolio.

Para o 9o ano, o tema central do livro é Arte e o gênero textual sugerido para orientar o desenvolvimento do portifolio é o blog. Nas páginas 8 e 9 do livro, logo após as listas de conteúdos e antes do início da unidade 1, o plano de aprendizagem da parte 1 é apresentado, juntamente à proposta do blog sobre arte. É apresentada também uma definição do que é o gênero blog e passos para iniciar o trabalho são introduzidos. Para escolas em que não é possível desenvolver blogs devido à deficiência no acesso à internet, sugere-se o desenvolvimento de um livreto sobre arte, que funcionaria como uma alternativa ao blog, elaborada no formato impresso.

Tal plano didático explicita a intenção do estudo situado da língua, proporcionando uma integração entre as unidades através da temática central da arte, concretizada na forma de produção em um gênero textual principal, 
o blog ou folheto, que comporá o portifolio e abrigará as demais atividades do livro com a abordagem de outros gêneros textuais e tópicos linguísticos. Embora o ensino de línguas através de gêneros textuais possa resultar em um novo engessamento do objeto de ensino, eles ajudam a sistematizar o estudo das produções discursivas no sentido de que possibilitam chamar a atenção dos alunos para o contexto de produção linguística, a situação comunicativa, o público alvo a quem se dirigir, o papel do autor e como ele se constitui e circunscreve os assuntos que abordará, o que pode colaborar para o desenvolvimento das habilidades de produção escrita e oral.

Após a explicitação e discussão de algumas características do plano didático, passo a referir-me à adequação do livro à turma em que será utilizado, a partir das categorias propostas por Ramos (2010), que permitem o delineamento de como o professor poderá fazer uso do livro em sua sala de aula, com seu grupo de alunos.

\subsection{Público-alvo}

A unidade será utilizada em uma turma de 21 alunos de faixa etária entre os 14 e os 16 anos. Os estudantes residem em um bairro rural de um município de porte médio da região sul do Brasil. A maioria ainda não se sente confiante para produzir enunciados complexos no idioma, visto que o estudam somente desde o 60 ano do ensino fundamental, em uma rede municipal de educação que lhes oferece apenas 55 minutos semanais de aula de LE. Parte dos alunos já afirmou que gosta de estudar o idioma, enquanto outros tantos manifestaram não ter apreço pelo objeto de estudo da disciplina. A turma possui um estudante com necessidades especiais, para quem as atividades de leitura e escrita precisam ser adaptadas. Por ser uma turma com relativamente pouco envolvimento e vivências na aprendizagem da língua inglesa, em razão 
das especificidades acima apresentadas, o fato de o livro discorrer sobre o tema da Arte, que atravessa dimensões anteriores da experiência desses aprendizes, pode atuar como um disparador do interesse dos estudantes pelas atividades ali propostas.

\subsection{Objetivos da unidade}

Os objetivos gerais da unidade estão explícitos no box Language in action, logo na primeira página, abaixo do título. São eles: aprender a falar sobre filmes e fazer recomendações. Acredito que são objetivos alcançáveis até certo ponto, porque envolvem a temática do cinema, presente no cotidiano dos alunos, objeto de sua atenção e que pode ativar conhecimentos prévios dos estudantes com relação à língua inglesa, visto que a indústria cinematográfica de massa é produzida dentro de um contexto em que o idioma é largamente utilizado. Creio que o tratamento dado ao tema dentro da unidade pode promover o alargamento dos horizontes culturais dos estudantes, os quais, se abordados pelo professor no sentido de estimular o cotejo das diferenças culturais e a reflexão sobre elas, pode contribuir para a formação de cidadãos críticos e reflexivos, preconizada nos documentos oficiais. É possível obter algum engajamento dos estudantes nas atividades de falar e escrever sobre cinema, dado seu interesse pelo assunto, o que pode promover sua aprendizagem e confiança no uso do idioma.

\subsection{Recursos}

Não há indicação de recursos a serem utilizados. Após uma leitura atenta de todas as atividades, pressupõese o uso do próprio livro didático, de materiais para escrever como lápis, caneta e borracha, possivelmente de um dicionário de língua inglesa, de folhas A4, pautadas e/ ou coloridas para a escrita da entrevista e da sinopse ou 
ainda o uso do laboratório de informática e da internet, caso a produção escrita ocorra no contexto da elaboração do portifolio no gênero blog. No entanto, a temática torna possível utilizar recursos como vídeos sobre a história do cinema, canções de trilhas sonoras de filmes famosos ou websites sobre arte para disparar a motivação e manter o interesse dos aprendizes.

\subsection{Visão de ensino/aprendizagem e de linguagem}

A visão sociointeracionista da aprendizagem e da linguagem subjacente ao livro fica explícita no próprio título da coleção, Alive!, seguido de um ponto de exclamação, o que já remete à dinamicidade da língua e da aprendizagem que se dão em contextos e situações em que as pessoas e sua linguagem estão "vivas".

Analisando a unidade cuidadosamente, nota-se que cada uma das seções inicia-se com o convite Let's, incitando os aprendizes a agir com a língua: Let's start! Let's read! Let's listen! Let's focus on the language! Let's talk! Let's read and sing! Let's act with words! A seção final, Let's act with words, que propõe uma atividade de redação de uma sinopse de filme para o portifolio anual, traz a metáfora "agir com palavras" como substituta do verbo "escrever".

No texto de apresentação ao aluno (MENEZES et al., p. 3), constam as expressões "interagir com seus colegas" e "usar a língua em situações cotidianas reais", além da proposição de que, para aprender inglês, "temos que ir além da sala de aula e procurar oportunidades de usar a língua em vários contextos". A apresentação da obra ao professor (MP, MENEZES et al., p. 3) inicia-se com a seguinte afirmação:

Esta coleção didática tem como pressuposto o ensino-aprendizagem de inglês como atividade 
social, sempre em movimento, efetivamente inserida na vida de alunos e professores, e não restrita a formalizações feitas em sala de aula.

Posteriormente, é apresentada a concepção de linguagem como um sistema semiótico complexo "que compreende processos biocognitivos, socio-históricos e político-culturais e que, como já dizia Saussure (1995), pertence ao domínio individual e ao domínio social" (MENEZES et al., Manual do Professor, p. 3), enfatizando uma concepção de "lingua(gem)" como um sistema vivo e dinâmico em constante evolução e mudança. Tais indícios e fatos podem apontar para o alinhamento do livro a uma perspectiva sociocultural de ensino e aprendizagem e enfatizam a qualidade do material em sua conformidade com os critérios do edital do PNLD.

\subsection{Syllabus subjacente à unidade}

O syllabus ou programa de estudos da unidade está organizado nas seções mencionadas acima, que enfatizam a aprendizagem da língua em suas quatro habilidades de uso: compreensão oral, leitura, produção oral e escrita.

A apresentação de conteúdos e solicitação de tarefas de produção ocorrem de forma progressiva. Na seção Let's start!, os estudantes são convidados a ler a respeito da história do cinema como forma de introduzir a temática, em seguida realizando exercícios de compreensão leitora e identificação de informações no texto como forma de introdução da voz passiva. $\mathrm{Na}$ seção Let's read!, logo após, os estudantes se envolvem em atividades de pré e pós-leitura de duas pequenas resenhas dos filmes The kid (O garoto), de Charles Chaplin e o Menino Maluquinho, de Ziraldo. Nesta seção, também são apresentados e propostos exercícios sobre tipos de filmes, além de curiosidades sobre Chaplin e os grandes festivais de cinema. 
$\mathrm{Na}$ seção Let's listen! os estudantes também se envolvem em atividades de pré e pós-leitura, mas de um texto oral, um trecho dialogado da animação infantil Procurando Nemo. Aqui são propostas ainda atividades comparativas de compreensão de variações linguísticas entre o inglês britânico e o americano, além de curiosidades sobre o festival de cinema Oscar. A seção seguinte, Let's focus on the language! prevê a leitura de um pôster de filme e a apresentação do tópico gramatical da unidade, a voz passiva, progredindo de exercício de identificação da voz passiva, transposição de trechos dos textos já lidos na unidade até a produção de sentenças a partir do preenchimento de lacunas. Essas duas seções iniciais promovem o insumo da língua contextualizado, vinculado à temática da unidade e aos tópicos linguísticos e sociolinguísticos abordados.

Na seção Let's talk!, o estudante é convidado a realizar uma entrevista com um colega e ser entrevistado por ele a respeito de curiosidades e preferências pessoais sobre cinema. A entrevista deve ser redigida por escrito e realizada oralmente, podendo depois ser anexada ao portifolio anual. O gênero entrevista possibilita a produção linguística revestida de uma finalidade comunicativa, a de descobrir as preferências e saberes dos colegas a respeito do tema, o que também pode se alinhar a uma perspectiva sociocultural do ensino e da aprendizagem de LE.

Em seguida, na seção Let's read and sing!, há uma atividade de ouvir, compreender e cantar a canção I don't wanna miss a thing, da banda de rock americana Aerosmith, que foi trilha sonora do filme deficçãocientífica Armageddon. Esta atividade, além de fornecer insumo, pode ainda contribuir para a manutenção do interesse pelo objeto de estudo. Por último, na seção Let's act with words!, o gênero sinopse de DVD é explorado através da capa e contracapa do DVD de Armageddon, e, mediante a exploração das características do gênero dispostas em uma 
tabela, o estudante é convidado a produzir uma sinopse do DVD de sua escolha a ser publicada no portifolio anual. $O$ caráter processual da produção escrita é enfatizado nesta seção, pois a produção da sinopse pelo aluno é feita por etapas de organização, preparação do primeiro rascunho, edição pelos pares e publicação final. Esta atividade final impõe desafios aos estudantes, que podem atuar em sua Zona de Desenvolvimento Proximal ${ }^{1}$ (VYGOTSKY, 1996) sendo auxiliados pelo professor e pelos demais colegas e promovendo a colaboração e o andaimento, primordiais à aprendizagem de LE a partir de uma perspectiva sociocultural (PINHO, 2013).

\subsection{Progressão dos conteúdos}

Como já implícito no subitem anterior, a progressão dos conteúdos ocorre do mais fácil para o mais difícil, com prioridade às habilidades de compreensão e leitura antes daquelas de produção oral e escrita. Efetivamente, a ativação dos conhecimentos prévios e de mundo dos alunos se dá antes da proposição da ativação e ampliação de seus conhecimentos de organização textual e sistêmicos, e a gramática é focalizada em textos advindos de contextos reais de comunicação e em uma situação de uso adequada ao gênero, no caso desta unidade, o emprego da voz passiva é apropriado aos gêneros descritivos resenha e sinopse.

O conhecimento estratégico aparece neste processo progressivo de autonomização do aluno no uso da língua, na proposição de tarefas por etapas e no projeto gráfico da unidade, repleta de ícones e símbolos da cultura cinematográfica, que podem ajudar na ativação dos conhecimentos dos estudantes e no estabelecimento de estratégias de memorização e aprendizagem por associação verbo-visual.
${ }^{1}$ Conceito elaborado por Vygotsky para se referir à distância entre o nível de desenvolvimento real, determinado pela capacidade de resolver um problema sem ajuda, e o nível de desenvolvimento potencial, determinado através de resolução de um problema em colaboração com outros companheiros, que, no âmbito da sala de aula, podem ser o professor ou colegas. 


\subsection{Textos}

Os textos são diversificados tanto com relação aos tipos como aos tópicos, pois, embora a temática geral gire em torno do cinema, alguns abordam a história do cinema, outros filmes específicos, personagens, narrativas, atores, música.

Acredito que a apresentação dos textos também é feita de maneira contextualizada, abordando amplamente a temática da unidade e promovendo interdisciplinaridade com as disciplinas de arte, história, ciência e língua portuguesa. As porções textuais presentes na unidade são adequadas à faixa etária e apresentam boa qualidade gráfica e visual no que concerne a ilustrações, diagramação, formatação etc, configurando-se como adequados às atividades propostas.

\subsection{Atividades}

Os objetivos de cada atividade estão explicitados em seus títulos: convidar os estudantes a usar a linguagem de acordo com a habilidade proposta para cada atividade. As instruções das atividades são claras e objetivas, mas dependem do professor para sua aplicabilidade, na medida em que alguns alunos não conseguiriam comprendê-las sozinhos.

Os enunciados conduzem à prática e à aprendizagem, embora não verifiquem o conhecimento do aluno quanto ao tópico ou o conhecimento sistêmico sendo abordado. O nível de controle das atividades varia entre mais e menos controladas, há atividades de interpretação e resposta pessoal e há aquelas que focam o conhecimento linguístico, solicitando respostas mais exatas e adequadas ao tópico gramatical e ao gênero textual, variando também entre tarefas e exercícios, entre as habilidades de compreensão e as de produção, da prática controlada para o uso autonomizado. O número 
de atividades parece adequado e suficiente aos objetivos gerais de aprendizagem propostos.

\subsection{Material suplementar}

Como material suplementar, a coleção oferece as seções Objetivos, temas e sugestões no manual do professor, nas quais constam, além dos objetivos gerais e específicos da unidade, textos adicionais sobre os temas abordados. Ao final das unidades do, há seções com atividades extras para serem utilizadas de acordo com as demandas de alunos e professor. Nas páginas 122, 123 e 124 são propostas 3 atividades extras sobre a temática do cinema: uma atividade de leitura sobre dois filmes com exercícios de preencher lacunas com estruturas na voz passiva, uma atividade de leitura e conversa telefônica que envolve a classificação de filmes de acordo com as faixas etárias admitidas para sua audiência e o convite a um colega de aula para assistir a um filme, e um exercício de palavras cruzadas sobre vocábulos pertencentes ao mundo do cinema. Levando em consideração o contexto no qual a unidade será utilizada, as sugestões e atividades extras são mais do que suficientes para a escassa carga horária de aulas de LE oferecidas aos alunos, de modo que, provavelmente, não haverá tempo hábil para explorá-las. Entretanto, oferecem ao professor uma gama maior de possibilidades dentre as quais selecionar de acordo com o interesse demonstrado pela turma.

\subsection{Flexibilidade da unidade}

Visto que a unidade está organizada em seções distintas, é possível adaptar as atividades ou suprimir algumas de suas etapas. No entanto, tais supressões e adaptações teriam como consequência o empobrecimento da abordagem da temática explorada na unidade. O uso de sequências alternativas à proposta também é possível, 
mas creio que não para as seções de abertura (Let's start.) e de fechamento (Let's act with words.) da unidade, imprescindíveis para a manutenção da coesão dos tópicos estudados na direção de um uso autoral da língua.

\subsection{Notas ao professor}

No livro do professor, foram encontradas, ao longo da Unit 1, 19 notas ao professor com sugestões sobre como ampliar as atividades, quando recorrer à seção Objetivos, temas e sugestões a fim de obter mais informações sobre os temas abordados, de como guiar o desenvolvimento das tarefas, dicas de tópicos linguísticos a serem revistos ou enfatizados em cada atividade e justificativas para o desenvolvimento de algumas das tarefas. O livro do professor contém também sugestões de respostas para os exercícios e atividades. De um modo geral, as instruções e sugestões ao professor podem promover uma qualificação de seu manejo da turma, pelo fato de lhe permitir desenvolver confiança nas aprendizagens que promove e facilitar os processos de gestão do tempo e dos modos de proposição e condução das tarefas junto aos estudantes.

\section{Considerações finais}

A análise leva à conclusão de que a unidade é adequada à faixa etária de meus alunos e seus objetivos apropriados ao nível de ensino para o qual foi elaborada, além de condizente, em suas linhas gerais, com uma perspectiva sociocultural ao ensino de línguas e adequada aos critérios do edital do PNLD. A análise da Unit 1 do livro Alive! para o 9o ano do ensino fundamental demonstrou ser mais uma oportunidade de formação continuada docente e aprendizagem para o ensino de LE.

Embora eu já esteja em contato com concepções sociointeracionistas de linguagem e de aprendizagem desde a graduação e a primeira etapa da pós-graduação 
(GOMES, 2008; 2013), o estudo da unidade didática levoume a notar distinções entre os materiais didáticos com que eu costumava ensinar e esta nova coleção didática que passo a utilizar em 2014. O caráter autêntico dos textos selecionados para compor o livro e o enfoque de prática social de uso da língua para finalidades e contextos variados sobressaem-se no processo de análise da unidade, o que leva a crer em uma efetiva e ascendente qualificação das coleções didáticas aprovadas para o PNLD.

No entanto, quanto à metodologia adotada, outras perguntas poderiam ser feitas que acarretariam na expansão das categorias de análise de Ramos (2010). Poderia se questionar em que medida as atividades propostas pelo livro contribuem para manter o interesse dos alunos pelo tema ali abordado. De que forma ajudam o professor a focar nas habilidades que os estudantes apresentam mais dificuldade? De que maneira podem levar à reflexão sobre os temas abordados? Como tais atividades promovem a colaboração? A reflexão metalinguística? Tais perguntas não cabem no escopo do presente trabalho, mas pode-se tentar respondê-las em estudos futuros.

Ainda cabe enfatizar a importância da avaliação crítica do professor quanto ao livro didático que seleciona e o uso que faz dele em sala de aula, pois o material didático deve estar a serviço da qualidade da aprendizagem de acordo com as necessidades de cada grupo de estudantes, não devendo ser adotado sem que o professor planeje suas aulas para atendê-las. Por mais bem projetado e produzido que seja, o livro didático ainda é um material que foi desenvolvido para atender um público geral, no caso das coleções do PNLD, o conjunto das escolas públicas de educação básica do Brasil. Portanto, o uso das coleções didáticas precisa, de qualquer forma, derivar de um processo de seleção e adaptação por parte do professor aos grupos em que serão utilizados, de preferência a partir de uma negociação 
com os alunos, pois, se forem simplesmente impostas, é possível que os estudantes não se engajem nas atividades. O processo de organização das atividades pedagógicas cabe ao professor, mas este deve compartilhá-lo com seus estudantes implicando-os na própria aprendizagem e fazendo uso crítico de artefatos mediadores de qualidade a fim de fomentar tal aprendizagem.

Apesar da visível qualidade da coleção e rigidez do processo de seleção efetuado no programa, outras limitações ainda interpelam o processo de qualificação educacional do ensino de LE no Brasil, como a carga horária reduzida e o pouco reconhecimento que o ensino/ aprendizagem de LE tem alcançado na escola regular. Infelizmente, receio que 40 horas-aula anuais não serão suficientes para desenvolver um trabalho consistente o bastante para explorar o livro todo e promover a consolidação da aprendizagem propiciada nas aulas. Conforme afirma Costa (2011, p. 337):

Uma aula por semana é insuficiente para o desenvolvimento de habilidades em LE, portanto, constata-se a necessidade de repensar a estrutura curricular, o que depende de ir além do número obrigatório de horas anuais.

A autora enfatiza que, por mais que o livro didático responda a critérios de avaliação e seleção de qualidade, não é o único instrumento que se pode utilizar e nem pode, sozinho, suprir as "deficiências que o sistema educacional brasileiro vem reproduzindo nos últimos anos" (COSTA, 2011, p. 338). Ela nos convoca a fazermos nossa parte para que o PNLD seja realmente um passo em direção a um novo horizonte na educação pública e para que os alunos possam aprender mais LE na escola, ao que reitero a necessidade urgente de modificações curriculares que fomentem este ensino e esta aprendizagem. 


\section{Referências}

COSTA, E. G. M. Lugar de aprender língua estrangeira é na escola: reflexões em torno do PNLD 2011. In: Revista Letras, Santa Maria, v. 21, n. 42, p. 315-340, jan./jun., 2011.

CUNNINGSWORTH, A. Evaluating and selecting EFL teaching materials. Londres: Heineman, 1984.

DIAS, R. Critérios para avaliação do livro didático de língua estrangeira no contexto do segundo ciclo do ensino fundamental. In: DIAS, R.;CRISTÓVÃO, V. L. L. (orgs.) $O$ livro didático de língua estrangeira: múltiplas perspectivas. Campinas: Mercado de Letras, 2009. p. 199-234.

EDITAL de convocação para inscrição no processo de avaliação e seleção de coleções didáticas para o Programa Nacional do Livro Didático - PNLD 2011. Brasília: Ministério da Educação, Fundo Nacional de Desenvolvimento da Educação, Secretaria de Educação Básica, 2010.

EDITAL de convocação para inscrição no processo de avaliação e seleção de coleções didáticas para o Programa Nacional do Livro Didático - PNLD 2014. Brasília: Ministério da Educação, Fundo Nacional de Desenvolvimento da Educação, Secretaria de Educação Básica, 2013.

GOMES, R. S. A aplicação da Pedagogia de Projetos no Estágio Supervisionado de ensino de Língua Estrangeira no Curso de Letras da UNISINOS. Trabalho de Conclusão. Curso de Letras. São Leopoldo: Universidade do Vale dos Sinos, 2008.

GOMES, R. S. Textualidade sincrética em blogs produzidos por estudantes do Ensino Fundamental. Dissertação de mestrado. Programa de Pós-Graduação em Linguística Aplicada. São Leopoldo: Universidade do Vale dos Sinos, 2013.

GRAY, J. (org.) Critical Perspectives on Language Teaching Materials. Basingstoke, Hampshire: Palgrave Macmillan, 2013. 
GUIA de livros didáticos: PNLD 2011: Língua Estrangeira Moderna: ensino fundamental: anos finais. Brasília: Ministério da Educação, Secretaria de Educação Básica, 2010.

GUIA de livros didáticos: PNLD 2014: Língua Estrangeira Moderna: ensino fundamental: anos finais. Brasília: Ministério da Educação, Secretaria de Educação Básica, 2013.

JOHNSON, K. Second language teacher education: a sociocultural perspective. New York: Routledge, 2009.

LANTOLF, J. P.; APPEL, G. Theoretical Framework: An Introduction to Vygotskyan Approaches to Second Language Research. In: LANTOLF, J. P.; APPEL, G. (orgs.) Vygotskyan Approaches To Second Language Research. New Jersey: Ablex Publishing Corporation, 1994. p. 01-32.

LANTOLF, J. P. Introducing Sociocultural Theory. In: LANTOLF, J. P. Sociocultural Theory and second language learning. Oxford University Press, 2004.

MENEZES, V.; BRAGA, J.; FRANCO, C. Alive!, inglês, 9o ano. 1a ed. São Paulo: Editora UDP, 2012.

OSS, D. I. B. O profissional do ensino de língua inglesa e seu objeto de ensino: do you know what I mean? Tese de doutorado. Programa de Pós-Graduação em Linguística Aplicada. São Leopoldo: Universidade do Vale dos Sinos, 2013.

PINHO, I. C. A tarefa colaborativa em inglês como língua estrangeira no ambiente virtual. Tese de doutorado. Programa de Pós-Graduação em Linguística Aplicada. São Leopoldo: Universidade do Vale dos Sinos, 2013.

RAJAGOPALAN, K. O papel eminentemente político dos materiais didáticos de inglês como língua estrangeira. In: SCHEYERL, D.; SIQUEIRA, S. (orgs.) Materiais didáticos para o ensino de línguas na contemporaneidade: contestações e proposições. Salvador: EDUFBA, 2012. 
RAMOS, R. C. G. O livro didático de língua inglesa para o ensino fundamental e médio: papéis, avaliação e potencialidades. In: DIAS, R.; CRISTÓVÃO, V. L. L. (orgs.) O livro didático de língua estrangeira: múltiplas perspectivas. Campinas: Mercado de Letras, 2009. p. 173-198.

SARMENTO, S.; SILVA, L. G. The book is (not) on the table: o programa nacional do livro didático no cotidiano escolar na educação linguística. In: Anais Eletrônicos do IX Congresso Brasileiro de Linguística Aplicada, v. 1, n. 1, 2012. Disponível em: www.alab.org.br/pt/eventos/ix-cbla/129. Acesso em: 22 dez. 2013.

VYGOTSKY, L. S. Pensamento e linguagem. Tradução de Jefferson Luiz Camargo. São Paulo: Martins Fontes, 1996. 
Anexo - critérios específicos da área de LE para a aprovação das coleções, conforme o edital do PNLD

\section{Critérios especificos da coleção}

1. reúne um conjunto de textos representativos das comunidades falantes da língua estrangeira, com temas adequados aos anos finais do ensino fundamental, que não veicule estereótipos nem preconceitos em relação às culturas estrangeiras envolvidas, nem à nossa própria em relação a elas;

2. seleciona textos que favoreçam o acesso à diversidade cultural, social, étnica, etária e de gênero manifestada na língua estrangeira, de modo a garantir a compreensão de que essa diversidade é inerente à constituição de uma língua e a das comunidades que nela se expressam;

3. contempla variedade de gêneros do discurso (orais e escritos), concretizados por meio de linguagem verbal, não verbal ou verbovisual, caracterizadora de diferentes formas de expressão na língua estrangeira e na língua nacional;

4. inclui textos que circulam no mundo social, oriundos de diferentes esferas e suportes representativos das comunidades que se manifestam na língua estrangeira;

5. discute relações de intertextualidades a partir de produções expressas em língua estrangeira e língua nacional;

6. propõe atividades de leitura comprometidas com o desenvolvimento da capacidade de reflexão crítica;

7. ressalta nas atividades de compreensão leitora o processo que envolve atividades de pré-leitura, leitura e pós-leitura;

8. explora estratégias de leitura, tais como localização de informações explícitas e implícitas no texto, levantamento de hipóteses, produção de inferência, compreensão detalhada e global do texto, dentre outras;

9. promove atividades de produção escrita compreendida como processo de interação, que exige a definição de parâmetros comunicativos, o entendimento de que a escrita se pauta em convenções relacionadas a contextos e gêneros de discurso e está submetida a processo de reelaboração;

10. promove a compreensão oral, com materiais gravados em mídia digitalizada, que incluam produções de linguagem e características da oralidade;

11. apresenta atividades que permitam o acesso a diferentes pronúncias e prosódias, em situação de compreensão oral intensiva (sons, palavras, sentenças), extensiva (compreensão global) e seletiva (compreensão pontual); 
12. oportuniza atividades de expressão oral em diferentes situações comunicativas, que estejam em inter-relação com necessidades de fala compatíveis com as do aluno das séries finais do ensino fundamental;

13. desenvolve atividades de leitura, escrita e oralidade, que sejam capazes de integrar propósitos e finalidades da aprendizagem da língua estrangeira;

14. propõe a sistematização de conhecimentos linguísticos, a partir do estudo de situações contextualizadas de uso da língua estrangeira;

15. oferece oportunidade de acesso a manifestações estéticas das diferentes comunidades que se identificam com a cultura estrangeira e com a nacional, com o propósito de desenvolver o prazer de conhecer produções artísticas;

16. explora atividades de uso estético da linguagem verbal, não verbal e verbo-visual, e contextualiza a obra em relação ao momento histórico e à corrente artística a que ela pertence;

17. propõe atividades que criem inter-relações com o entorno da escola, estimulando a participação social dos jovens em sua comunidade como agentes de transformações;

18. propõe atividades de avaliação e de autoavaliação que integrem os diferentes aspectos que compõem os estudos da linguagem nesse nível de ensino, buscando harmonizar conhecimentos linguísticodiscursivos e aspectos culturais relacionados à expressão e à compreensão na língua estrangeira;

19. utiliza ilustrações que reproduzam a diversidade étnica, social e cultural das comunidades, das regiões e dos países em que as línguas estrangeiras estudadas são faladas;

20. articula o material oferecido na mídia digital que acompanha a coleção com temas, textos e atividades previstas no livro do aluno;

21. proporciona articulação entre o estudo da língua estrangeira e manifestações que valorizam as relações de afeto e de respeito mútuo, a criatividade e a natureza lúdica que deve ter esse ensino, compatíveis com o perfil do aluno das séries finais do ensino fundamental.

Critérios especificos do manual do professor

1. explicita a organização da coleção (volumes impressos e mídia digital), os objetivos pretendidos, a orientação teórico-metodológica assumida para os estudos da linguagem e, em particular, para o ensino de línguas estrangeiras;

2. articula a proposta teórico-metodológica assumida no manual do professor com o que se apresenta nos livros do aluno e na mídia digital que integra a coleção;

3. relaciona a proposta didática da obra aos documentos organizadores e norteadores dos últimos anos do ensino fundamental, no que se refere às línguas estrangeiras; 
4. oferece referências suplementares (sítios de internet, livros, revistas, filmes, outros materiais) que apoiem atividades propostas no livro do aluno e na mídia que integra/compõe a coleção;

5. apresenta atividades complementares para o desenvolvimento tanto da compreensão como da produção em língua estrangeira, mantendose os critérios de diversidade de gêneros de discurso, seus possíveis suportes e contextos de circulação;

6. inclui informações que favoreçam a atividade do professor, proporcionando-lhe condições de expandir seus conhecimentos acerca da língua estrangeira e de traços culturais vinculados a comunidades que se expressam por meio dessa língua;

7. sugere respostas às atividades propostas no livro do aluno, sem que tenham caráter exclusivo nem restritivo, em especial quando se refira a questões relacionadas à diversidade linguística e cultural expressa na língua estrangeira;

8. concretiza, por meio de propostas de projetos, atividades, eventos, o tratamento do lúdico, dos afetos, do respeito mútuo e da criatividade como componentes fundamentais para o processo de aprendizagem do aluno das séries finais do ensino fundamental;

9. elucida seu compromisso com a valorização dos saberes advindos da experiência do professor, favorecendo a aproximação respeitosa entre saberes teóricos e saberes práticos;

10. formaliza seu envolvimento com a construção de uma proposta de ensino de língua estrangeira que esteja associada ao compromisso de oferecer uma formação escolar construtora da cidadania do aluno dos anos finais do ensino fundamental, afastando-se de orientações teórico-metodológicas que não a favoreçam. 